\title{
Evaluating Route and Frequency Design of Bus Lines Based on Data Envelopment Analysis with Network Epsilon-Based Measures
}

\author{
Yiling Deng $\mathbb{D}^{1}$ and Yadan Yan $\mathbb{i}^{2}$ \\ ${ }^{1}$ College of Civil Engineering and Architecture, Zhejiang University of Technology, China \\ ${ }^{2}$ School of Civil Engineering, Zhengzhou University, China \\ Correspondence should be addressed to Yadan Yan; yanyadan@zzu.edu.cn
}

Received 14 February 2019; Revised 21 April 2019; Accepted 7 May 2019; Published 26 May 2019

Academic Editor: Oded Cats

Copyright ( $) 2019$ Yiling Deng and Yadan Yan. This is an open access article distributed under the Creative Commons Attribution License, which permits unrestricted use, distribution, and reproduction in any medium, provided the original work is properly cited.

\begin{abstract}
Increasing the efficiency of bus transit remains to be a challenge of urban transportation. Since the optimization of bus routes and their frequencies is significant for transit efficiency, this study aims to develop two data envelopment analysis (DEA) models using network epsilon-based measures (NEBMs). The first NEBM model adopts twelve indicators to evaluate the rationality of the route network design; the second NEBM model uses nine indicators to evaluate the efficiency of the frequency setting. Both NEBM models can simultaneously consider radial and nonradial inputs and outputs and dig into details of the "input/output transformation box." Finally, the bus transit system of Nanjing in China is used as a case study. Results show that the overall efficiency of network route design is higher than that of frequency setting. According to comparisons between descriptive statistics of the top and bottom performers, inefficiency causes of bottom performers are identified and corresponding improvement measures are suggested. The proposed models are helpful for the development of bus transit systems and can be applied on a yearly/monthly basis.
\end{abstract}

\section{Introduction}

A high-quality bus transit system will attract urban citizens to use, which furthermore helps to alleviate traffic congestion, reduce air pollution, and promote social fairness. Given growing needs and limited funding, regular assessment of bus transit systems is significant for transit agencies to identify best practices and underperforming routes. Actions can thus be taken to amend inefficient routes, thereby improving the whole transit system.

Besides, China's large cities are experiencing rapid growth. Urban land use and travel patterns are changing every day. A large number of urban rail transit systems have been put into operation, serving more and more residents. The development of bus transit system in China is facing enormous challenges. According to Statistical Bulletin of China Ministry of Transport, the number of bus passengers has been declining for three consecutive years. Bus passengers decreased by $3 \%$ in 2017 , although the number of buses increased by $7 \%$ and the operating mileage increased by $9 \%$ [1]. Transit agencies are gradually aware of the importance of improving bus networks to accommodate new travel patterns and coordinate with urban rail transit. However, most bus networks evolve based on historical development and rarely undergo major changes for decades. Lack of clear-cut and comprehensive methods to evaluate the "goodness" of bus routes is also hinderance to changes of bus routes.

Hence, this study proposed two data envelopment analysis (DEA) models using network epsilon-based measures (NEBMs) to evaluate bus route design and frequency setting. Following the introductory section, Section 2 illustrates the NEBM model. Section 3 introduces the evaluation frameworks and indicators. Section 4 presents the application in Nanjing of China. Conclusions and future work are offered in Section 5. 
1.1. Literature Review. A cost-effective transit planning process is comprised of five efficient components: (1) route network designing, (2) frequency setting, (3) timetabling, (4) vehicle scheduling, and (5) crew scheduling and rostering [2]. The first two, usually termed strategic planning, are most complicated and significant for transit efficiency [3]. In theory, the search for optimum bus routes and frequencies should be carried out by formulating the definition of routes and frequencies as a mathematical programming problem and solved by simulation [4] or heuristics algorithms [5]. While in practice, bus routes and frequencies are usually designed using manual approaches, relying on transportation planners' local knowledge, experience, and intuition. However, both methods cannot fully meet the needs of bus transit planning. Mathematical programming methods are too complicated in application; manual approaches usually fail to provide a systematic view. Hence, combining manual approaches with indicator-based evaluations is one method to address the complexity of bus networks. Indicator-based evaluations can provide a systematic view of bus networks and are much easier to use than mathematical programming approaches.

Key performance indicator (KPI) analysis and composite score analysis are two main indicator-based evaluation approaches. KPI analysis establishes goals or thresholds for indicators; composite score analysis normalizes and weights indicators to get a composite score. Both methods are used in many practical transit planning circumstances. For example, the TCRP report "elements needed to create high ridership transit systems" summarized various route-level and systemlevel measures and benchmarks, including design measures such as coverage, span of service, frequency of service, and travel time, and performance measures such as productivity, crowding, and reliability [6]. Sun and Guan used indicators such as weighted average path length and weighted global efficiency to measure vulnerability of the urban metro network from the operation perspective [7]. Deng used seven indicators including residential area coverage, nonresidential area coverage, and land use mix to identify improvable bus route groups based on cluster analysis [8]. However, in KPI analysis and composite score analysis, the thresholds and weights are always determined subjectively.

Other studies adopted modern benchmarking tools, such as data envelopment analysis (DEA). DEA is a nonparametric technique using linear programming to evaluate the relative efficiency of a set of peer units called decision-making units (DMUs) [9]. Each DMU uses resources (inputs) to produce its goods or services (outputs). DEA does not assume a functional form relating inputs to outputs but establishes a linear production frontier to monitor the conversion of inputs to outputs. Each DMU's relative efficiency is calculated by comparing its performance with the estimated production frontier - the "best practice" of a peer or a combination of peers. DEA has been widely used to evaluate organizations' work in the same industry, for example, schools, banks, factories, and utilities. In the field of public transit, the majority of existing research focused on evaluating transit operators or transit systems from management perspectives $[10,11]$. For bus routes, most studies focused on operational performance evaluation, as shown in Table 1. Zhu et al. proposed a threestage DEA approach to incorporate operating environment effects and statistical noise into the efficiency measurement framework [12]. Li et al. adopted a bootstrap super-dataenvelopment analysis (SDEA) model for route-level transit operational efficiency assessment [13]. Zhang et al. used a mixed data envelopment analysis-stochastic frontier analysis (DEA-SFA) model to evaluate the operational efficiency of an urban bus transit system at different periods and tried to explore better operating strategies [14]. Jin-Seok et al. proposed a network DEA model to evaluate bus service by considering desirable outputs such as total riders and service satisfaction scores as well as undesirable outputs such as $\mathrm{CO}_{2}$ emissions [15]. Few studies combined operational performance evaluation with structural performance evaluation to make the model more suitable for bus route planning. Lao and Liu used two DEA models to examine operational efficiency and spatial effectiveness of bus routes [16]. Zhang et al. adopted super-efficient DEA model to evaluate bus routes from three aspects, that is, planning, operation, and service [17]. Ran et al. assessed operational efficiency and access equity via a combination of DEA and multiobjective spatial optimization techniques [18]. A wide variability exists in the selection of DEA inputs and outputs in existing studies.

1.2. Objectives and Contributions. Although many indicatorbased methods, especially DEA models, have been implemented in the field of transit planning, there are several limitations in the evaluation framework, methodology, and indicator design aspects. For evaluation framework, previous studies mainly focused on transit operation but rarely considered network route design. The efficiencies of route and frequency design are both critical to the well-being of bus routes. Evaluating them holistically can provide a comprehensive assessment for bus routes. For methodology, existing studies mostly used conventional DEA models, which had some shortcomings in evaluating bus route efficiency. First, conventional DEA models are radial models that consider the radial measures of efficiency but neglect nonradial slacks. Bus routes cannot be identified as completely efficient when the efficiency is 1 but the slacks are nonzero. Second, the inputs or outputs can only change proportionally in conventional DEA models. Meanwhile, for bus route evaluation, radial and nonradial inputs and outputs should be considered simultaneously, because the inputs and outputs not necessarily change proportionally. Third, conventional DEA models pay little attention on details of the "input to output transformation box," which hinders deep understanding of the transformation process.

Hence, the NEBM model is used in this paper to evaluate bus routes, which could combine the radial and nonradial measures of efficiency into a unified framework and examine the inner workings of the production process. For indicator design, previous studies treated each bus route independently. We design connectivity and overlapping indicators to consider the transfer and interdependence between bus routes and between bus routes and metro lines. In addition, Baidu heat map data are used to solve the problem of lacking detailed residential and employment data. 
TABLE 1: Summary of DEA models in existing studies.

\begin{tabular}{|c|c|c|c|}
\hline Authors & Inputs & Outputs & Model \\
\hline $\begin{array}{l}\text { Zhu } \\
\text { et al. [12] }\end{array}$ & labour, fuel, vehicles & $\begin{array}{l}\text { operating revenue, average operating } \\
\text { speed, average punctuality rate }\end{array}$ & three-stage DEA \\
\hline $\begin{array}{l}\mathrm{Li} \\
\text { et al. [13] }\end{array}$ & $\begin{array}{l}\text { operating cost, total capacity, vehicle mileage, } \\
\text { frequency, } 1 \text { /directness, operational speed }\end{array}$ & $\begin{array}{l}\text { passenger volume, load factor at peak } \\
\text { load point, satisfaction }\end{array}$ & bootstrap SDEA \\
\hline $\begin{array}{l}\text { Zhang } \\
\text { et al. [14] }\end{array}$ & $\begin{array}{l}\text { corrected fares, waiting time cost, reliability } \\
\text { penalty cost, in-vehicle time cost }\end{array}$ & passenger-kilometres, total income & mixed DEA-SFA \\
\hline $\begin{array}{l}\text { Hahn } \\
\text { et al. [15] }\end{array}$ & $\begin{array}{l}\text { possession and operating costs, ratio of median } \\
\text { bus stops, overlapped route lengths }\end{array}$ & $\begin{array}{l}\text { total riders, service satisfaction scores, } \\
\qquad \mathrm{CO}_{2} \text { emissions }\end{array}$ & network DEA \\
\hline $\begin{array}{l}\text { Lao and Liu } \\
{[16]}\end{array}$ & $\begin{array}{l}\text { operational input: operation time, round-trip } \\
\text { distance, number of bus stops } \\
\text { spatial input: commuters using buses, population } \\
65 \text { and older, persons with disabilities }\end{array}$ & $\begin{array}{l}\text { operational output: total number of } \\
\text { passengers } \\
\text { spatial input: total number of } \\
\text { passengers }\end{array}$ & DEA \\
\hline $\begin{array}{l}\text { Sun } \\
\text { et al. [17] }\end{array}$ & $\begin{array}{c}\text { planning input: dispatching frequency, total } \\
\text { number of stops, demand detour coefficient, } \\
\text { average minimum transfer time } \\
\text { operation input: dispatching frequency, total } \\
\text { number of stops, bus arrival state rate } \\
\text { service input: dispatching frequency, total number } \\
\text { of stops, peak hour maximum standing rate, peak } \\
\text { hour delay rate }\end{array}$ & $\begin{array}{l}\text { planning output: } 500-\mathrm{m} \text { travel demand } \\
\text { coverage, } 500-\mathrm{m} \text { transfer rate } \\
\text { operation output: average route } \\
\text { operation speed, average on-road } \\
\text { operation speed, on time arrival rate } \\
\text { service output: transit ridership }\end{array}$ & super-efficient DEA \\
\hline $\begin{array}{l}\text { Wei } \\
\text { et al. [18] }\end{array}$ & $\begin{array}{l}\text { operational input: operating mileage, operation } \\
\text { time, number of operating buses }\end{array}$ & $\begin{array}{l}\text { operational output: average daily } \\
\text { ridership }\end{array}$ & $\begin{array}{l}\text { DEA and multi-objective } \\
\text { spatial optimization }\end{array}$ \\
\hline
\end{tabular}

\section{Methodology}

2.1. EBM Model. DEA is a nonparametric method to evaluate the relative efficiencies of a set of comparable DMUs with multiple inputs and outputs. Two of the conventional DEA models are the CCR model developed by Charnes, Cooper, and Rhodes in 1978 and the BCC model developed by Banker, Charnes, and Cooper in 1984 [9]. Both models are named after their developers. Both models consider the radial measures of efficiency, where the inputs or outputs change proportionally. A main difference between two models is that CCR model assumes constant returns to scale (CRS) in its production possibility set, while BCC model takes the variable returns to scale (VRS) assumption, which means that efficiency may increase or decrease with a change of size in input or output.

Assume that the data set is $(\mathrm{Y}, \mathrm{X})$. $\mathrm{Y}$ and $\mathrm{X}$ denote the $s \times n$ matrix of outputs and $m \times n$ matrix of inputs, respectively. $Y=\left\{y_{i j}\right\}^{s \times n} ; X=\left\{x_{i j}\right\}^{m \times n} \cdot n, s$, and $m$ represent the number of DMUs, outputs, and inputs, respectively. The input-oriented CCR model can get the efficiency $\theta^{*}$ of $\mathrm{DMU}_{0}$ by solving the following linear programming:

$$
\begin{aligned}
\theta^{*} & =\min \theta \\
\text { s.t. } \theta x_{i 0} & =\sum_{j=1}^{n} \lambda_{j} x_{i j}+S_{i}^{-} \quad i=1,2, \ldots, m \\
y_{r 0} & \leq \sum_{j=1}^{n} \lambda_{j} y_{r j} \quad r=1,2, \ldots, s \\
\lambda & \geq 0, S_{i}^{-} \geq 0
\end{aligned}
$$

where $x_{i j}$ and $y_{r j}$ stand for the ith input and the $r$ th output of the $j$ th DMU. $S$ is the input slacks and $\lambda$ is the input weight. The subscript " 0 " signifies the DMU which is under evaluation. If the efficiency of $\mathrm{DMU}_{0}$ is $1, \mathrm{DMU}_{0}$ is technically efficient; if its efficiency is less than 1, it is technically inefficient.

The input-oriented CCR model is based on proportional reduction of inputs. In order to observe slacks of DMUs, the Slacks-Based Measure (SBM) model was proposed by Tone [19]. SBM model relaxes the proportionality and allows independent changes of associated slacks in inputs or outputs. The efficiency $\tau^{*}$ of the input-oriented SBM is calculated by the following model:

$$
\begin{aligned}
\tau^{*} & =\min 1-\frac{1}{m} \sum_{i=1}^{m} \frac{s_{i}^{-}}{x_{i 0}} \\
\text { s.t. } x_{i 0} & =\sum_{j=1}^{n} \lambda_{j} x_{i j}+S_{i}^{-} \quad i=1,2, \ldots, m \\
y_{r 0} & \leq \sum_{j=1}^{n} \lambda_{j} y_{r j} \quad r=1,2, \ldots, s \\
\lambda & \geq 0, S_{i}^{-} \geq 0
\end{aligned}
$$

Tone and Tsutsui suggested that CCR model and SBM model had some shortcomings [20]. The radial CCR model neglects the effect of nonradial slacks $S^{-}$in the efficiency $\theta^{*}$. The nonradial SBM model may lose the proportionality in the inputs or outputs, because $S^{-}$is not necessarily proportional to $x_{0}$. Therefore, they proposed the epsilon-based measure (EBM) to simultaneously consider both the radial and nonradial measures in a unified DEA framework. A new index called "affinity index" was used to measure similarity and defined a scalar measure epsilon $(\varepsilon)$, and a scheme for applying weights to the slacks based on principal component 
analysis was also proposed [20]. The efficiency $\gamma^{*}$ of the input-oriented EBM model is calculated as follows:

$$
\begin{aligned}
\gamma^{*} & =\min \theta-\varepsilon_{x} \sum_{i=1}^{m} \frac{w_{i}^{-} s_{i}^{-}}{x_{i 0}} \\
\text { s.t. } \theta x_{i 0} & =\sum_{j=1}^{n} \lambda_{j} x_{i j}+S_{i}^{-} \quad i=1,2, \ldots, m \\
y_{r 0} & \leq \sum_{j=1}^{n} \lambda_{j} y_{r j} \quad r=1,2, \ldots, s \\
\lambda & \geq 0, S_{i}^{-} \geq 0
\end{aligned}
$$

where $w_{i}$ is the relative importance of $i$ th input and satisfies $\sum_{i=1}^{m} w_{i}^{-}=1$ and $w_{i}^{-} \geq 0 . \varepsilon_{x}$ is a parameter that depends on the dispersion degree of inputs. $w_{i}$ and $\varepsilon_{x}$ are offered in advance of measuring the efficiency. In EBM model, $\theta$ represents the radial properties and $\varepsilon_{x} \sum_{i=1}^{m}\left(w_{i}^{-} s_{i}^{-} / x_{i 0}\right)$ represents the nonradial properties. $\varepsilon_{x}=0$ implies that EBM model changes to be a CCR model and $\varepsilon_{x}=1$ implies that EBM model changes to be an SBM model. $w_{i}$ depends on the affinity degree between inputs. The higher the affinity degree between inputs is, the more weights are allocated to the inputs.

2.2. NEBM Model. Conventional EBM methods make no assumptions concerning the internal operations of a DMU and treat each DMU as a "black box" by considering only the initial inputs consumed by the DMU and the final outputs produced by the DMU. Madjid et al. extended the EBM model and proposed the Network EBM (NEBM) model for solving network DEA problems, which allowed one to examine in more detail the inner workings of the production process [21]. The NEBM model combines the radial and nonradial measures of efficiency into a unified framework.

$\mathrm{x}_{\mathrm{h}}^{\mathrm{ij}}$ and $\mathrm{y}_{\mathrm{h}}^{\mathrm{rj}}$ represent the $i$ th input $\left(\mathrm{i}=1,2, \ldots, \mathrm{m}_{\mathrm{h}}\right)$ and the $r$ th output $\left(r=1,2, \ldots, \mathrm{s}_{\mathrm{h}}\right)$ of the $h$ th division $(\mathrm{h}=1,2, \ldots, \mathrm{k})$ in the $j$ th DMU $(\mathrm{j}=1,2, \ldots, \mathrm{n})$, respectively. $z_{f_{\left(h, h^{\prime}\right)}^{\left(h, h^{\prime}\right)}}$ represents the intermediate measure between the $h$ th division and the $h^{\prime}$ th division of the $j$ th DMU. The subscript $f_{\left(h, h^{\prime}\right)}$ represents the number of intermediate measures sent from the $h$ th division to the $h^{\prime}$ th division $f_{\left(h, h^{\prime}\right)}=1,2, \ldots, F_{\left(h, h^{\prime}\right)}$. The NEBM model is presented as follows:

$$
\begin{aligned}
& \gamma^{*}=\min \sum_{\substack{h=1 \\
\theta_{k}, \lambda, S^{-}}}^{k} W_{h}\left(\theta_{h}-\varepsilon_{x}^{h} \sum_{i=1}^{m_{h}} \frac{w_{i}^{h-} s_{i}^{h-}}{x_{i 0}^{h}}\right) \\
& \text { s.t. } \theta_{h} x_{i 0}^{h}=\sum_{j=1}^{n} \lambda_{j}^{h} x_{i j}^{h}+S_{i}^{h-} \quad i=1,2, \ldots, m_{h}, h=1,2, \ldots, k \\
& y_{r 0}^{h} \leq \sum_{j=1}^{n} \lambda_{j}^{h} y_{r j}^{h} \quad r=1,2, \ldots, s_{h}, h=1,2, \ldots, k \\
& \sum_{j=1}^{n} z_{f_{\left(h, h^{\prime}\right)}^{\left(h, h^{\prime}\right)}}^{(j)} \lambda_{j}^{h}=\sum_{j=1}^{n} z_{f_{\left(h, h^{\prime}\right)}^{\left(h, h^{\prime}\right)} j} \lambda_{j}^{h^{\prime}}, \quad f_{\left(h, h^{\prime}\right)}=1,2, \ldots, F_{\left(h, h^{\prime}\right)}, \forall\left(h, h^{\prime}\right) \\
& \theta_{h} \leq 1 \quad h=1,2, \ldots, k \\
& \lambda_{j}^{h} \geq 0 \quad j=1,2, \ldots, n, h=1,2, \ldots k \\
& S_{i}^{h-} \geq 0 \quad i=1,2, \ldots m_{h}, h=1,2, \ldots, k
\end{aligned}
$$

where $w_{i}^{h-}$ is the weight of the ith input sent from the $h$ th division that satisfies $\sum_{i=1}^{m_{h}} w_{i}^{h-}=1$. $\varepsilon_{x}^{h}$ is determined based on the dispersion degree of parameters associated with the inputs of the $h$ th division. $S_{i}^{h-}$ represents the slack for the $i$ th input in the $h$ th division. $W_{h}$ represents the weight of the $h$ th division and is determined by the decision-makers. The third constraint is related to the intermediate products where the right side represents the products sent from the $h$ th division and the left side shows the same products sent to the $h^{\prime}$ th division. The efficiency score of each division for the NEBM is calculated as follows:

$$
\gamma_{\text {NEBM }}^{h}=\theta_{h}-\varepsilon_{x}^{h} \sum_{i=1}^{m_{h}} \frac{w_{i}^{h-} s_{i}^{h-}}{x_{i 0}^{h}}
$$

\section{Indicator Design}

3.1. Evaluation Framework. This study aims to address the main concerns in strategic planning which have rarely been evaluated collectively in existing studies. Two data envelopment analysis (DEA) models using network epsilon-based measures (NEBM) are constructed.

The first NEBM model is used to evaluate the rationality of the route network design. A "well-being" bus route ought to meet passengers' travel needs in terms of spatial coverage, transfer potentials, and travel time saving and its operation will thus gain high ridership. Hence, inputs are designed from the following perspectives: (1) the number of stops and route length should be kept under a certain bound; (2) the bus route hardly deviates from the shortest path so as to reduce the operator's costs and improve the reliability; (3) the bus route should be irreplaceable by other routes. Five indicators, the number of stops, route length, route directness, bus overlapping, and metro overlapping, are used as inputs of stage 1. Four indicators, the residential coverage, employment coverage, bus connectivity, and metro connectivity, are used as intermediate inputs/outputs. Two indicators, that is, the off-peak operation speed and the peak operation speed, are used as inputs of stage 2 . That is because buses operate in the urban road or highway contexts, which are often interrupted by traffic congestion, signals, pedestrian, or vehicle crossing. The off-peak operation speed and peak operation speed, which are mostly determined by external environment, are used as inputs of stage 2 rather than intermediate inputs/outputs. Annual average daily ridership is used as the final output. The framework and indices of route network design evaluation are illustrated in Figure 1.

The second NEBM model is used to evaluate the effectiveness of frequency setting. A general objective of frequency setting is to gain the profit (i.e., ridership) and minimize operation costs (which are related to the number of buses, the number of drivers, and daily operation time) under constraints of route length and reliability. Three indicators, the number of buses, the number of drivers, and daily operation time, are used as inputs of stage 1. Two indicators, that is, the peak frequency and the off-peak frequency, are used as intermediate inputs/outputs. Two indicators, the offpeak on-time arrival rate and the peak on-time arrival rate, 


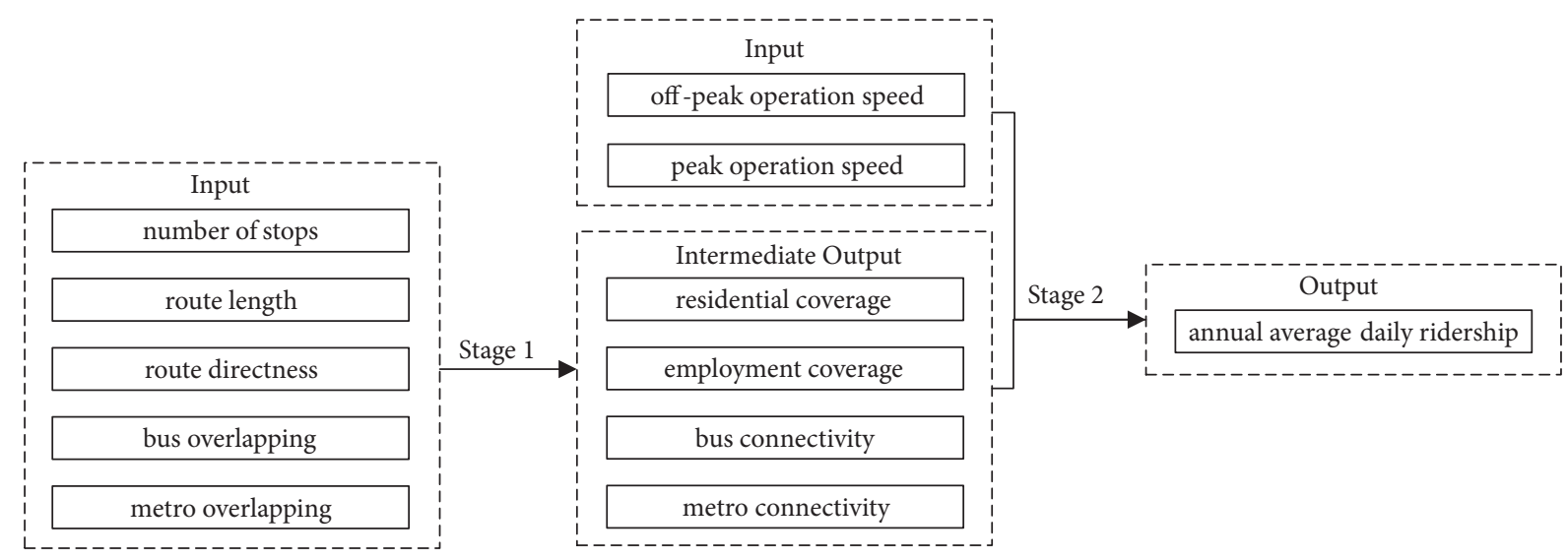

FIGURE 1: The framework and indices of route network design evaluation.

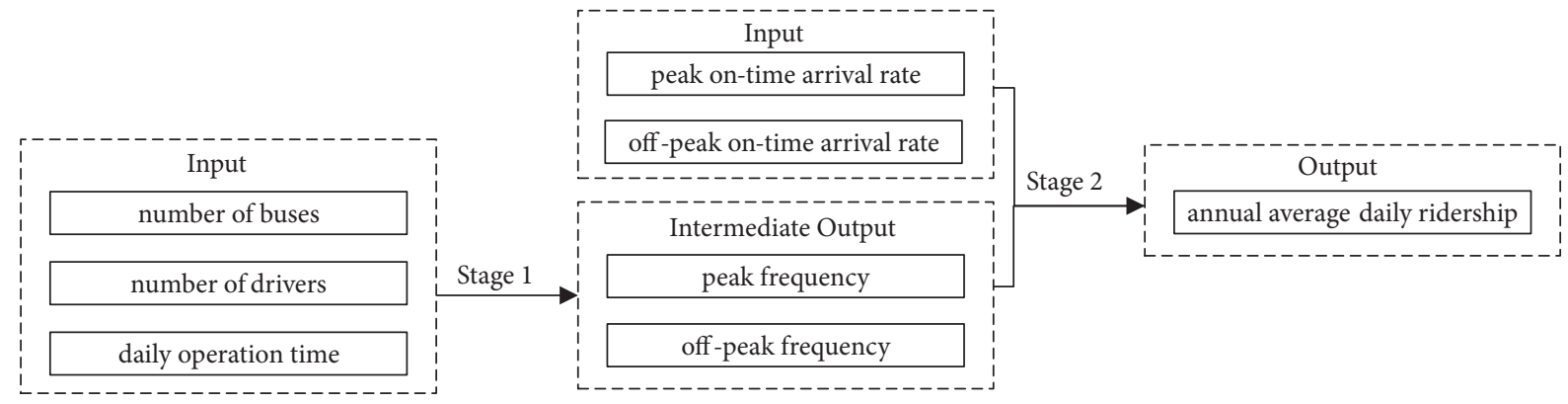

FIGURE 2: The framework and indices of frequency setting evaluation.

are used as inputs of stage 2. Annual average daily ridership is used as the final output. The framework and indices of frequency setting evaluation are illustrated in Figure 2.

\subsection{Indices of Network Route Design}

3.2.1. Number of Stops. The total number of stops on a bus route is a conventional transit planning indicator, which can be directly obtained from transit agencies.

3.2.2. Route Length. The route length of bus routes can be calculated using ArcGIS, which should not be too long for profitability and reliability reasons.

3.2.3. Route Directness. Bus riders prefer to travel directly from their origin to destination. Route directness reflects route's deviation from a linear path and travel time of bus riders. It also considers the additional mileage incurred by a bus trip compared to the same trip by car or other modes of transportation. Calculation of the route directness is presented in the following equation:

$$
\text { route directioness } s_{u}=\frac{\text { route length }}{\text { Euclidean distance }_{u}}
$$

where $u$ represents labels of bus routes. Route length and Euclidean distance can be calculated using ArcGIS.
3.2.4. Bus and Metro Overlapping. Most previous studies treated bus routes independently without considering route interchange and overlapping. We propose bus and metro overlapping indices as well as bus and metro interchange indices to solve this problem. If the travel demand between two bus stops on one bus route can be severed by another bus route, we define it as overlapping. The higher overlapping is, the more chance that a bus route can be replaced. Assuming that a bus route has $p$ stops within $300 \mathrm{~m}$ from any bus stop of another bus route, the bus overlapping score equals $C_{p}^{2}$. The permutation formula means that there are $C_{p}^{2}$ combinations of boarding and alighting stops can be served by other bus routes. For example, if there are 3 overlapped stops, trips between stop 1 and 2, stop 2 and 3, and stop 1 and 3 can take other bus routes. The bus overlapping score equals $C_{3}^{2}$. The final bus overlapping is calculated as the sum of bus overlapping scores applied to the whole bus network divided by the number of bus stop pairs, as shown in the following equations:

$$
\begin{aligned}
& \text { bus overlapping }{ }_{u}=\sum_{v=1, v \neq u}^{a} \frac{\text { bus overlapping } \text { score }_{u v}}{C_{c}^{2}} \\
& \text { bus overlapping } \text { score }_{u v}=C_{p}^{2}
\end{aligned}
$$

where $a$ is total number of bus routes; $c$ is total number of bus stops on bus route $u ; p$ is number of overlapped bus stops between bus route $u$ and $v ; u$ and $v$ are labels of bus routes. 
The same formulas with some minor modifications can be applied to calculate metro overlapping:

$$
\begin{aligned}
& \text { metro overlapping } \\
& =\sum_{t=1}^{b} \frac{\text { metro overlapping score }}{u t} \\
& \text { metro overlapping score } \text { ut }=C_{q}^{2}
\end{aligned}
$$

where $b$ is total number of metro routes; $c$ is total number of bus stops on bus route $u ; q$ is number of overlapped bus stops between bus route $u$ and metro route $t ; u$ are labels of bus routes; $t$ are labels of metro routes.

3.2.5. Residential and Employment Coverages. Detailed residential and employment data are needed to calculate residential and employment coverages. However, the official population census (related to residential data) and economic census (related to employment data) conducted every five years or ten years is outdated and coarse-scaled. Even worse, only a few large cities have conducted economic census. To ensure applicability and transferability of indicators, the heat map from Baidu Map is used. As the largest online map app in China, Baidu Map has more than 200 million registered users and receives 3.5 million position requests every day [22]. Baidu Map gathers location-based data from smartphone apps using its location services to generate the heat map, which provides an interpretable visual representation of spatial distribution of its users.

A multistep procedure was developed to calculate the residential and employment coverages. Firstly, assuming that most Baidu Map users stay in work places at 10 am and at home at $10 \mathrm{pm}$, a python script is used to crawl heat maps at 10 am and $10 \mathrm{pm}$ in a workday to represent employment distribution and residential distribution. These crawled heat maps are saved as PNG images. Secondly, the opacity band of each PNG image is imported in ArcGIS as a raster layer. Then georeferencing is conducted to match the raster layer to bus stop data, which is in the WGS84 coordinate system. Finally, opacity values of the raster layer within $300 \mathrm{~m}$ from each bus stop are extracted and averaged to get the heat value of each bus stop using extract point value tool and raster calculation tool in ArcGIS. These heat values range from 52 to 179. For computational convenience, all heat values are subtracted by 51 and the final range is from 1 to 128 . The procedure is illustrated in Figure 3.

The residential coverage for each bus route is calculated as the sum of heat values of all bus stops on the route divided by the number of bus stops, as shown in the following equation:

$$
\text { residential coverage }{ }_{u}=\sum_{g=1}^{c} \frac{\text { residential heat value }}{u g}
$$

where $u$ are labels of bus routes; $g$ are labels of bus stops on bus route $u$; $c$ is total number of bus stops on bus route $u$. The same formula can be applied to calculate the employment coverage. The calculation standardizes the residential and employment coverages and eliminates effects of the number of bus stops.
3.2.6. Bus and Metro Connectivity. An efficient public transit network should encourage transfer between bus routes and between bus routes and metros. The geographic data of bus stops and metro stops are used to calculate bus connectivity and metro connectivity. For a bus route, if at least one stop is within $300 \mathrm{~m}$ from any stop of another bus route, bus connectivity score equals 1 . The final bus connectivity of the bus route is the sum of bus connectivity score applied to the whole bus network divided by the number of bus stops as shown in the following equations:

$$
\text { bus connectivity } y_{u}=\sum_{v=1, v \neq u}^{a} \frac{\text { bus connectivity score } \text { suv }_{u}}{c}
$$

bus connectivity score uv $_{\text {. }}$

$$
= \begin{cases}1, & \text { exist at least one transfer stop } \\ 0, & \text { otherwise }\end{cases}
$$

where $a$ is total number of bus routes; $c$ is total number of bus stops on bus route $u ; u$ and $v$ are labels of bus routes.

The same formulas with some minor modifications can be applied to calculate metro connectivity.

$$
\begin{aligned}
& \text { metro connectivity }_{u} \\
& \quad=\sum_{t=1}^{b} \frac{\text { metro connectivity score }_{u t}}{c} \\
& \text { metro connectivity score }_{u t} \\
& = \begin{cases}1, & \text { exist at least one transfer stop } \\
0, & \text { otherwise }\end{cases}
\end{aligned}
$$

where $b$ is total number of metro routes; $c$ is total number of bus stops on bus route $u$; $u$ are labels of bus routes; $t$ are labels of metro routes.

3.2.7. Operation Speed. Running time records from transit agencies are used to calculate average route operation speeds in peak period and off-peak period, respectively. Operation speed is defined as the length of bus route divided by the average running time, as presented in the following equation:

$$
\text { operation } \text { speed }_{u}=\frac{\text { route lengt }}{\text { average running time }}
$$

where $u$ are labels of bus routes.

Since inputs should have the characteristics of smaller values being better (less resource needed for a given output), (21) is introduced to convert the "more-the-better" type of route connectivity to "less-the-better" type of route connectivity.

$$
\begin{aligned}
{\text { operation } \text { speed }_{u}^{\prime}=} & \max (\text { operation speed }) \\
& - \text { operation } \text { speed }_{u}
\end{aligned}
$$



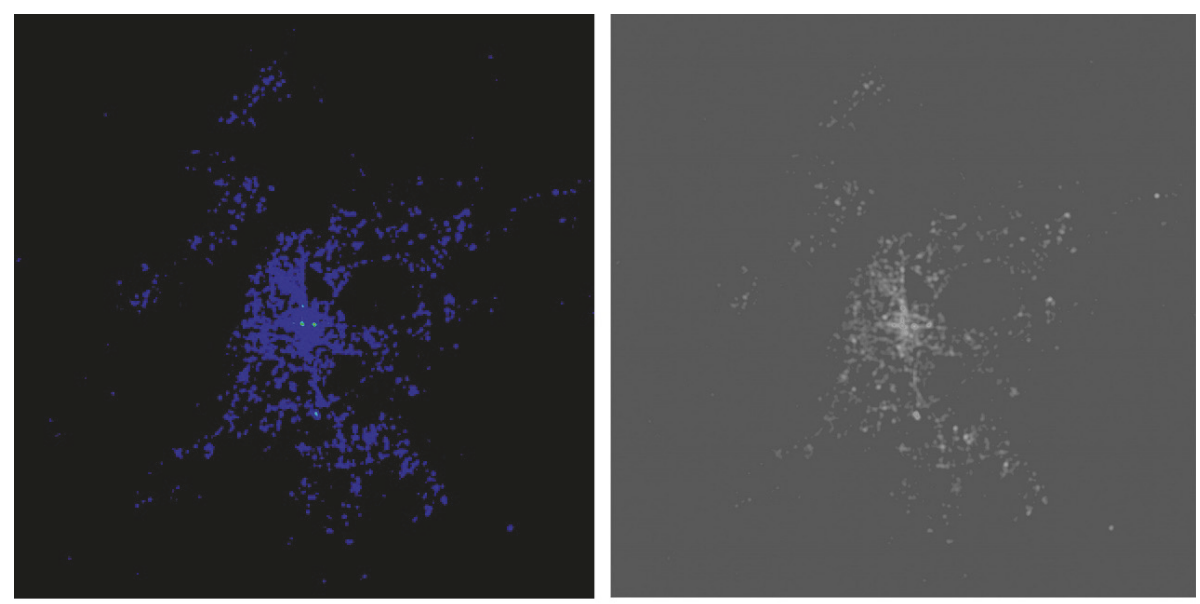

Step 1: crawl heat map from Baidu Map

Step 2: import opacity band in ArcGIS as a raster layer

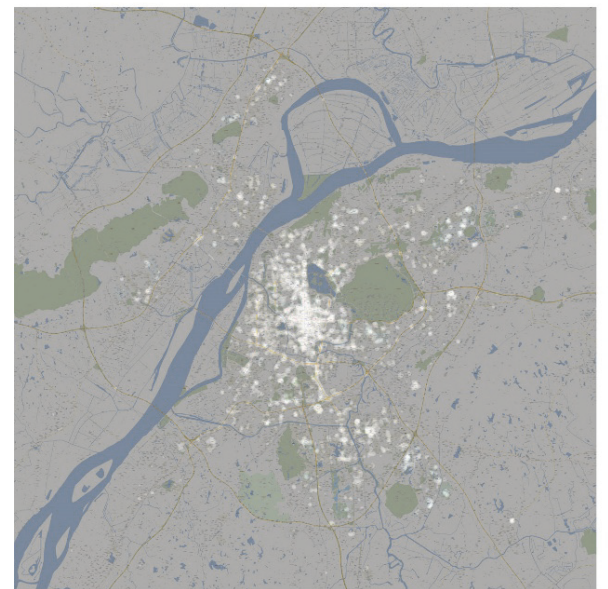

Step 3: georeferencing

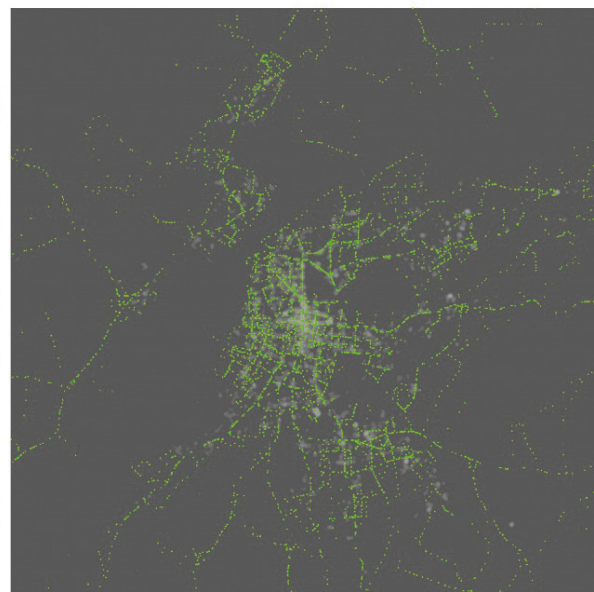

Step 4: extract opacity value and average

FIGURE 3: Calculation procedure of residential and employment coverages.

3.2.8. Annual Average Daily Ridership. Annual average daily ridership is the most widely used indicator of efficiency evaluation, since it accurately measures the actual output of a bus system, taking both the number of passengers and the revenues of providers into account. It should be noted that ticket fares of urban arterial bus routes in most Chinese cities are fixed at $1 \mathrm{RMB}$ or $2 \mathrm{RMB}$, which do not depend on distance travelled.

\subsection{Indices of Frequency Setting}

3.3.1. Number of Buses. The lengths of buses range from 8 to $12 \mathrm{~m}$. The $12 \mathrm{~m}$ long bus with the capacity of 70 persons is regarded as a standard bus. Other types of buses are converted to standard buses according to their capacities. Therefore, the total number of standard buses for each bus route can be obtained.

3.3.2. Number of Drivers. Since the data of other indirect employees are unavailable, only full-time drivers are taken into account, which can be directly obtained from transit agencies.
3.3.3. Daily Operation Time. The daily operation time can be directly obtained from transit agencies.

3.3.4. Frequency. The frequency can be directly obtained from transit agencies. Since most urban arterial bus routes adopt the two-frequency scheme (i.e., different frequencies applied in peak period and off-peak period), peak frequency and off-peak frequency are used in the model.

3.3.5. On-Time Arrival Rate. On-time arrival rate is defined as the ratio of buses arriving at end stop on time in peak period and off-peak period, respectively. Using running time records, on-time arrival rate is calculated as the number of on-time arrival runs divided by the number of total runs:

$$
\text { on-time arrival rate } e_{u}=\frac{\text { on-time arrival runs }}{\text { total runs }_{u}}
$$

where $u$ are labels of bus routes.

Since inputs should have the characteristics of smaller values being better (less resource needed for a given output), (23) is introduced to convert the "more-the-better" type of 


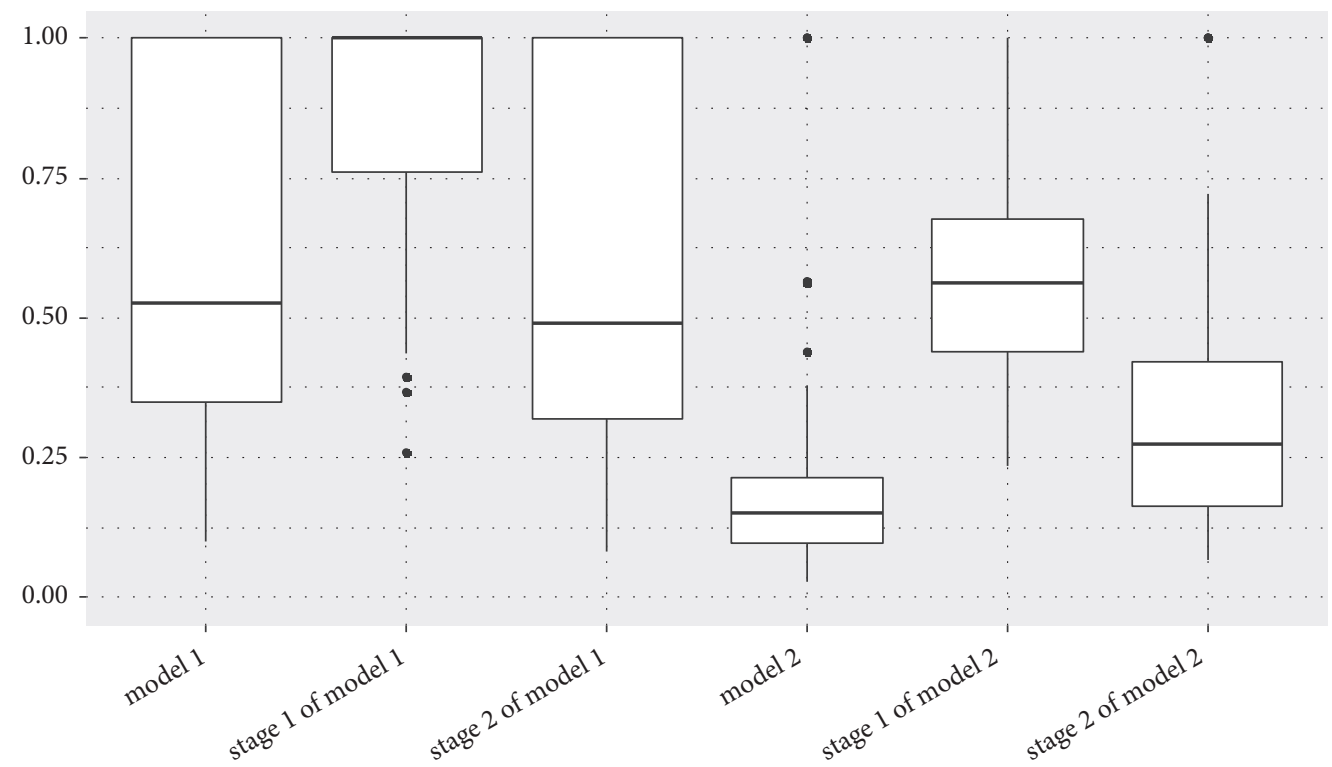

Figure 4: Distributions of efficiency rating.

route connectivity to "less-the-better" type of route connectivity.

$$
\begin{aligned}
\text { operation } \operatorname{speed}_{u}^{\prime}= & \max (\text { operation speed }) \\
& - \text { operation } \text { speed }_{u}
\end{aligned}
$$

3.3.6. Annual Average Daily Ridership. Same as Section 3.2.8, Annual Average Daily Ridership.

\section{Case Study}

Nanjing in China had a population of 8.16 million in 2016. Like other China's large cities, it is experiencing rapid urbanization and motorization. In the last decade, Nanjing's builtup area reached $653 \mathrm{~km}^{2}$ by an annual growth rate of $11.9 \%$; private car ownership reached 866 thousand by an annual growth rate of $25.3 \%$ [23].

The transit network of Nanjing consisted of 410 bus routes and 7 metro lines in 2016. Out of the 410 bus routes, 185 bus routes were urban arterial routes; 126 bus routes were urban local routes; 81 bus routes were rural routes; and the rest were tour routes or night routes. The total average daily transit ridership was 3.35 million.

The performance of bus routes with different characteristics varies greatly. For example, rural routes are usually inefficient, because they serve rural areas with low population density. In this study, NEBM models are built for urban arterial routes, urban local routes, and rural routes, separately. The tour routes and night routes were not modelled due to their small quantities from the DEA modelling perspective. For brevity, only NEBM models of urban arterial routes are illustrated.
4.1. Descriptive Statistics of Indicators. 19 indicators for 185 urban arterial bus routes in Nanjing are calculated, respectively. Descriptive statistics of these indicators are shown in Table 2. "sd" denotes the standard deviation.

4.2. Model Application and Results Analysis. Based on selected indicators, two NEMB models are built to measure the route design and frequency setting efficiencies. The efficiency scores should be smaller than or equal to 1.0 and a higher score indicates a more efficient status. Figure 4 is a box plot of efficiency distributions for two overall and four divisional efficiencies. The mean efficiency of route design is 0.60 and that of frequency setting is 0.18 . The efficiencies of route design are more widely distributed than efficiencies of frequency setting. The proposed models have relatively low efficiency scores because we incorporate many DMUs and apply NEBMs. The efficiency value of NEBM is lower than that of traditional DEA, because NEBM adopts intermediate inputs/outputs to reflect internal or linking activities of DMUs. The efficiency of stage 2 is much lower than that of stage 1 for both NEBMs, which suggests that the input-output process in stage 2 needs more improvement.

The best way to obtain a comprehensive picture of bus route performance is to compare the efficiency of route design with the efficiency of frequency setting. The correlation coefficient between two efficiencies is 0.13 , which is positive but rather small. It indicates that bus routes with high route design efficiency scores may not have high frequency setting efficiency scores and vice versa. The geographic location and environment of bus routes are illustrated using GIS. We use nature breaks to classify bus routes based on two overall efficiencies. Figures 5 and 6 provide snapshots of the efficiency classifications for all urban arterial bus routes operated in Nanjing. Bus routes with high efficiencies (colored red) are best performers and can be served as benchmarks for 
TABLE 2: Descriptive statistics of indicators.

\begin{tabular}{|c|c|c|c|c|c|}
\hline Type & Indicator & $\min$ & $\max$ & mean & sd \\
\hline \multicolumn{6}{|l|}{ Model 1} \\
\hline \multirow{5}{*}{ Input of stage 1} & number of stops & 10.0 & 38.0 & 24.4 & 5.1 \\
\hline & route length $(\mathrm{km})$ & 5.7 & 45.5 & 16.0 & 4.8 \\
\hline & route directness & 1.1 & 2.8 & 1.6 & 0.3 \\
\hline & bus overlapping & 0.0 & 15.8 & 2.2 & 1.7 \\
\hline & metro overlapping & 0.0 & 0.2 & 0.0 & 0.0 \\
\hline \multirow{4}{*}{ Intermediate input/output } & residential coverage & 1.0 & 27.7 & 8.9 & 4.1 \\
\hline & employment coverage & 1.5 & 44.7 & 15.9 & 7.5 \\
\hline & bus connectivity & 0.0 & 6.5 & 2.6 & 1.1 \\
\hline & metro connectivity & 0.0 & 0.1 & 0.0 & 0.0 \\
\hline \multirow{2}{*}{ Input of stage 2} & off-peak operation speed $(\mathrm{km} / \mathrm{h})$ & 10.5 & 34.8 & 18.9 & 3.8 \\
\hline & peak operation speed $(\mathrm{km} / \mathrm{h})$ & 8.4 & 26.8 & 16.6 & 3.4 \\
\hline Output & annual average daily ridership & 2122 & 36642 & 13768 & 7029 \\
\hline \multicolumn{6}{|l|}{ Model 2} \\
\hline \multirow{3}{*}{ Input of stage 1} & number of buses & 2.0 & 71.0 & 25.5 & 11.3 \\
\hline & number of drivers & 5.0 & 195.3 & 69.9 & 34.0 \\
\hline & daily operation time (h) & 7.0 & 19.2 & 16.2 & 1.5 \\
\hline \multirow{2}{*}{ Intermediate input/output } & off-peak frequency (veh/h) & 3.3 & 17.1 & 8.2 & 2.7 \\
\hline & peak frequency (veh/h) & 3.8 & 30.0 & 11.6 & 4.6 \\
\hline \multirow{2}{*}{ Input of stage 2} & off-peak on-time arrival rate (\%) & 0.0 & 98.0 & 53.9 & 31.1 \\
\hline & peak on-time arrival rate (\%) & 0.0 & 90.0 & 47.4 & 31.4 \\
\hline Output & annual average daily ridership & 2122 & 36642 & 13768 & 7029 \\
\hline
\end{tabular}

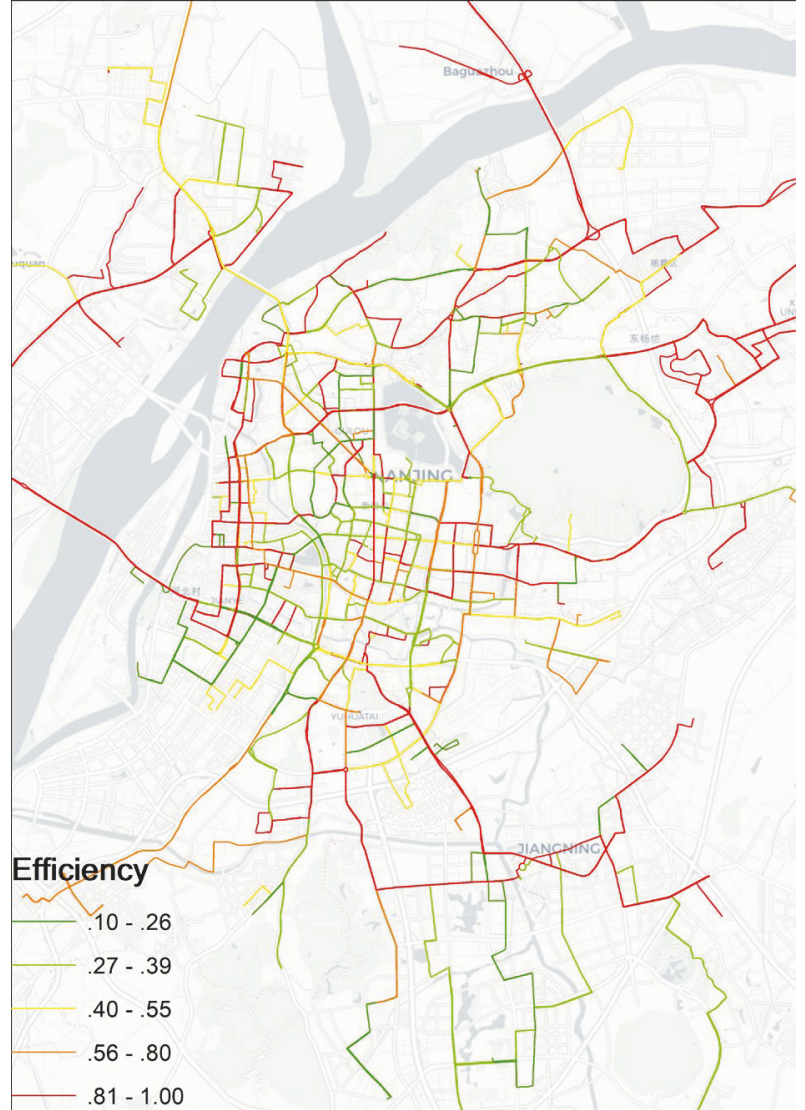

FIGURE 5: Bus routes classified by network route design efficiencies.

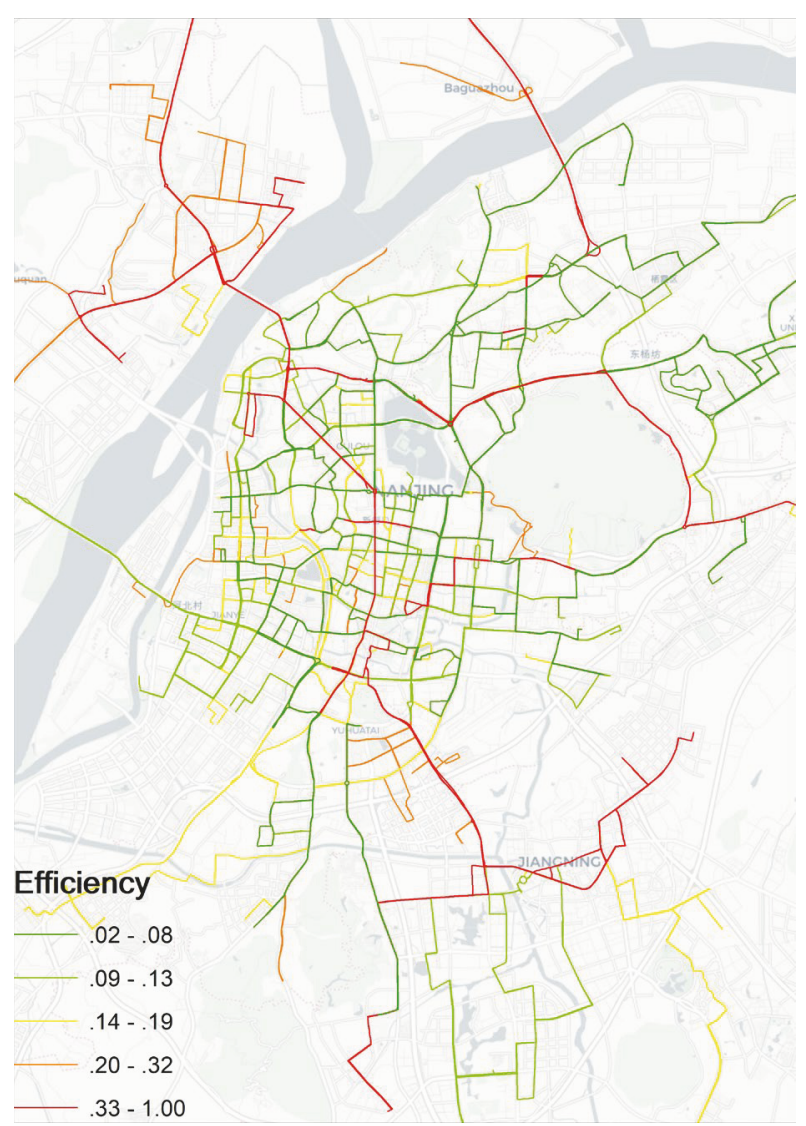

FIgURE 6: Bus routes classified by frequency setting efficiencies. 
TABLE 3: Top and bottom performers and efficiency scores.

\begin{tabular}{|c|c|c|c|c|c|c|}
\hline \multirow{2}{*}{ Bus routes } & \multicolumn{3}{|c|}{ Model 1} & \multicolumn{3}{|c|}{ Model 2} \\
\hline & Overall & Stage 1 & Stage 2 & Overall & Stage 1 & Stage 2 \\
\hline \multicolumn{7}{|c|}{ Top performers } \\
\hline 100 & 1.00 & 1.00 & 1.00 & 0.34 & 0.71 & 0.47 \\
\hline 101 & 0.94 & 0.88 & 1.00 & 1.00 & 1.00 & 1.00 \\
\hline 151 & 1.00 & 1.00 & 1.00 & 1.00 & 1.00 & 1.00 \\
\hline 157 & 0.86 & 1.00 & 0.78 & 0.44 & 0.66 & 0.67 \\
\hline 183 & 1.00 & 1.00 & 1.00 & 0.32 & 0.62 & 0.52 \\
\hline 55 & 1.00 & 1.00 & 1.00 & 1.00 & 1.00 & 1.00 \\
\hline \multicolumn{7}{|c|}{ Bottom performers } \\
\hline 113 & 0.20 & 0.55 & 0.25 & 0.06 & 0.40 & 0.16 \\
\hline 114 & 0.19 & 0.50 & 0.21 & 0.06 & 0.39 & 0.16 \\
\hline 121 & 0.23 & 0.44 & 0.23 & 0.03 & 0.39 & 0.07 \\
\hline 134 & 0.23 & 0.65 & 0.23 & 0.12 & 0.61 & 0.19 \\
\hline 160 & 0.11 & 0.63 & 0.10 & 0.11 & 0.33 & 0.31 \\
\hline 318 & 0.17 & 0.50 & 0.22 & 0.08 & 0.43 & 0.19 \\
\hline 53 & 0.10 & 1.00 & 0.08 & 0.10 & 0.65 & 0.15 \\
\hline 66 & 0.27 & 0.74 & 0.25 & 0.07 & 0.62 & 0.11 \\
\hline 73 & 0.25 & 0.65 & 0.27 & 0.10 & 0.62 & 0.17 \\
\hline JN21 & 0.22 & 0.62 & 0.18 & 0.11 & 0.39 & 0.29 \\
\hline
\end{tabular}

other routes to improve their efficiencies. Bus routes with middle efficiencies (colored yellow) are effective performers and can be maintained and supported. Bus routes with low efficiencies (colored green) are worst performers, which should be redesigned.

Figure 7 shows the top and bottom performers. Table 3 displays the top and bottom performers in terms of efficiency. Efficiencies of bus routes 100,101, 151, 157, 183, and 55 rank highest in both route design and frequency setting aspects. Further analyses on annual average daily ridership indicate that these four bus routes also have the highest volumes. Efficiencies of bus routes 113,114,121, 134, 160, and so forth rank lowest in both aspects. For these bus routes, the planning and operation should be strengthened to attract more passengers.

Table 4 shows descriptive statistics of indicators of the top and bottom performers. There are several interesting facets to these results.

First, compared with top performers, bottom performers are associated with very low ridership.

Second, for Model 1, bottom performers "over-invest" in the number of stops and route directness, but "underproduce" residential and employment coverage and bus connectivity (stage 1). The efficiency of stage 2 is even worse than that of stage 1. Compared with top performers, bottom performers "invest" about $93 \%$ of residential coverage and $83 \%$ of employment coverage but "produce" $31 \%$ of annual average daily ridership (stage 2). Strategies to improve efficiency involve optimizing bus stop locations to increase the bus interchange potential and to get closer to residential and employment area and, more importantly, to achieve the good balance between residential and employment coverages.

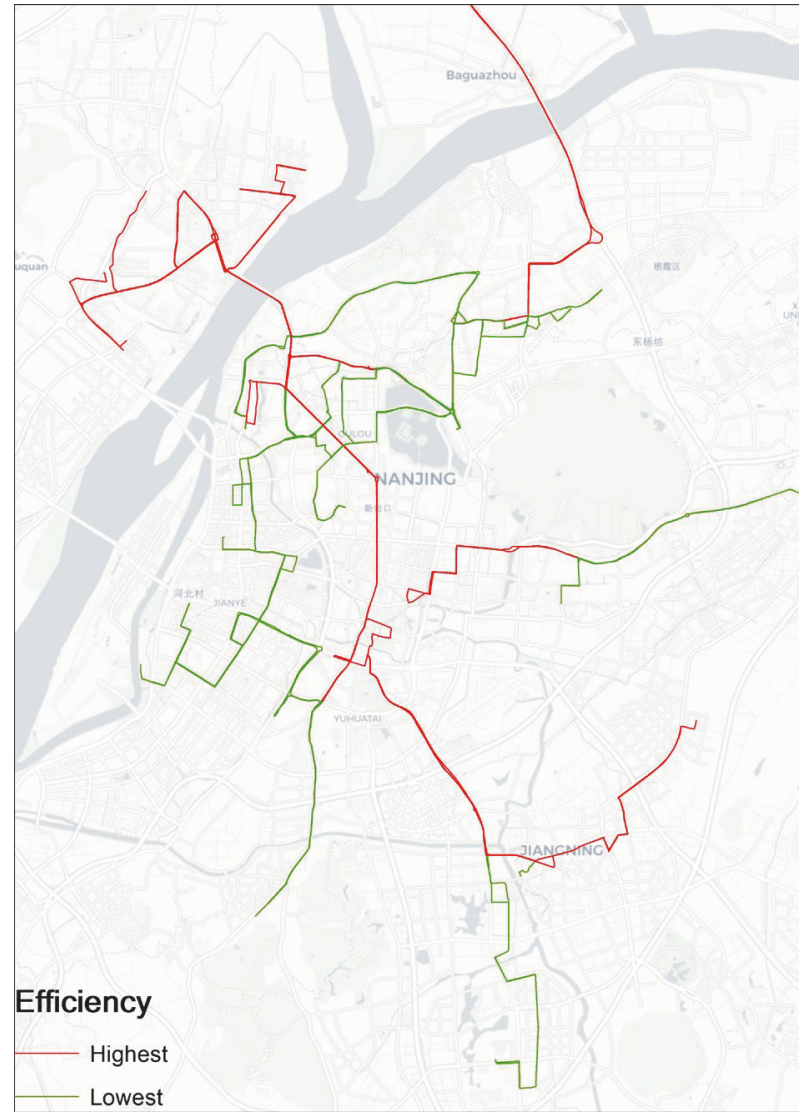

FIgURE 7: Top and bottom performers.

It requires further analysis of demographics and commuting patterns at neighbourhood level. 
TABLE 4: Descriptive statistics of indicators of the top and bottom performers.

\begin{tabular}{|c|c|c|c|c|c|}
\hline \multirow{2}{*}{ Type } & \multirow{2}{*}{ Indicator } & \multicolumn{2}{|c|}{ Bottom performers } & \multicolumn{2}{|c|}{ Top performers } \\
\hline & & mean & sd & mean & sd \\
\hline \multicolumn{6}{|l|}{ Model 1} \\
\hline \multirow{5}{*}{ Input of stage 1} & number of stops & 27.8 & 4.3 & 22.0 & 5.3 \\
\hline & route length $(\mathrm{km})$ & 15.2 & 2.6 & 15.5 & 1.6 \\
\hline & route directness & 1.8 & 0.5 & 1.6 & 0.3 \\
\hline & bus overlapping & 2.0 & 1.2 & 2.5 & 0.9 \\
\hline & metro overlapping & 0.0 & 0.0 & 0.0 & 0.0 \\
\hline \multirow{4}{*}{ Intermediate input/output } & residential coverage & 8.3 & 2.9 & 8.9 & 4.6 \\
\hline & employment coverage & 13.1 & 3.9 & 15.8 & 7.1 \\
\hline & bus connectivity & 2.0 & 0.7 & 3.3 & 1.1 \\
\hline & metro connectivity & 0.0 & 0.0 & 0.0 & 0.0 \\
\hline \multirow{2}{*}{ Input of stage 2} & off-peak operation speed $(\mathrm{km} / \mathrm{h})$ & 15.7 & 1.8 & 15.1 & 4.2 \\
\hline & peak operation speed $(\mathrm{km} / \mathrm{h})$ & 9.7 & 1.5 & 9.9 & 4.1 \\
\hline Output & annual average daily ridership & 6500 & 2962 & 21044 & 8401 \\
\hline \multicolumn{6}{|l|}{ Model 2} \\
\hline \multirow{3}{*}{ Input of stage 1} & number of buses & 19.6 & 8.1 & 28.0 & 10.0 \\
\hline & number of drivers & 51.4 & 23.2 & 79.5 & 28.5 \\
\hline & daily operation time (h) & 15.6 & 0.7 & 17.1 & 1.1 \\
\hline \multirow{2}{*}{ Intermediate input/output } & off-peak frequency (veh/h) & 6.7 & 2.2 & 8.6 & 2.3 \\
\hline & peak frequency (veh/h) & 8.8 & 3.4 & 18.2 & 7.1 \\
\hline \multirow{2}{*}{ Input of stage 2} & off-peak on-time arrival rate (\%) & 26.6 & 19.9 & 64.8 & 39.3 \\
\hline & peak on-time arrival rate (\%) & 19.9 & 18.2 & 62.2 & 35.4 \\
\hline Output & annual average daily ridership & 6500 & 2962 & 21044 & 8401 \\
\hline
\end{tabular}

Third, for model 2, the efficiency of stage 2 is still worse than that of stage 1 . Bottom performers "invest" about $78 \%$ of off-peak frequency and $48 \%$ of peak frequency but only "produce" $31 \%$ of annual average daily ridership (stage 2 ). In order to improve efficiencies, strategies involve modifying service frequencies and schedules.

\section{Conclusions}

The dramatic expansion of urban land use and the introduction of urban rail transit change the travel patterns in China's large cities. The need to adequately evaluate and improve bus routes has been accentuated. Two NEBM models are proposed for bus routes evaluation so as to identify deficiencies and bring out optimization strategies in terms of route design and frequency setting. To the best of our knowledge, it is the first attempt to apply NEBM model to evaluate bus routes. This model is much easier to use than mathematical programming approaches in assisting the development of bus transit systems. It can be applied on a yearly/monthly basis and easily transferred to other cities.

Besides, this study focuses on route design and frequencies setting, which mainly reflect the transit operator perspectives. From the passenger perspective, travel time, reliability, and in-vehicle comfort are their concerns. Passengers' requirements of travel time and reliability are consistent with transit operators, which are reflected in route directness, operation speed, and on-time arrival rate indicators. But their requirements of in-vehicle comfort are not fully considered in the proposed model. As passenger flows and bus services fluctuate at different time periods, the service quality indicator can be calculated using Automatic Fare Collection (AFC) or Automatic Passenger Counting (APC) data. Extending the model by relaxing the output variables and investigating how external traffic conditions influence transit efficiency will be important future works.

\section{Data Availability}

The [19 indicators of 185 urban arterial routes] data of Nanjing, China, used to support the findings of this study are available from the corresponding author upon request.

\section{Conflicts of Interest}

The authors declare that there are no conflicts of interest regarding the publication of this paper.

\section{Acknowledgments}

This research is funded by the National Natural Science Foundation of China (51608483) and Zhejiang Philosophy and Social Science Planning Project (19NDQN351YB).

\section{References}

[1] 2017 Transportation Industry Development Statistics Bulletin, Ministry of Transport of the People's Republic of China, 2018. 
[2] A. Ceder, "Urban transit scheduling: Framework, review and examples," Journal of Urban Planning and Development, vol. 128, no. 4, pp. 225-244, 2002.

[3] V. Guihaire and J. K. Hao, "Transit network design and scheduling: a global review," Transportation Research Part A: Policy and Practice, vol. 42, no. 10, pp. 1251-1273, 2008.

[4] S. Asadi Bagloee and A. A. Ceder, "Transit-network design methodology for actual-size road networks," Transportation Research Part B: Methodological, vol. 45, no. 10, pp. 1787-1804, 2011.

[5] D. J. Sun, Y. Xu, and Z.-R. Peng, “Timetable optimization for single bus line based on hybrid vehicle size model," Journal of Traffic and Transportation Engineering (English Edition), vol. 2, no. 3, pp. 179-186, 2015.

[6] Elements Needed to Create High Ridership Transit Systems, Transportation Research Board, 2005.

[7] D. J. Sun and S. Guan, "Measuring vulnerability of urban metro network from line operation perspective," Transportation Research Part A: Policy and Practice, vol. 94, pp. 348-359, 2016.

[8] Y. Deng, "An indicator-based method for bus routing adjustment," in Green Intelligent Transportation System and Safety. GITSS 2017, vol. 503 of Lecture Notes in Electrical Engineering, pp. 695-706, 2019.

[9] W. D. Cook and L. M. Seiford, "Data envelopment analysis (DEA) - thirty years on," European Journal of Operational Research, vol. 192, no. 1, pp. 1-17, 2009.

[10] J.-S. Hahn, D.-K. Kim, H.-C. Kim, and C. Lee, "Efficiency analysis on bus companies in Seoul city using a network DEA model," KSCE Journal of Civil Engineering, vol. 17, no. 6, pp. 1480-1488, 2013.

[11] Y.-C. Chiou, L. W. Lan, and B. T. H. Yen, "Route-based data envelopment analysis models," Transportation Research Part E: Logistics and Transportation Review, vol. 48, no. 2, pp. 415-425, 2012.

[12] W. Zhu, X. Yang, and J. Preston, "Efficiency measurement of bus routes and exogenous operating environment effects on efficiency," Transportation Planning and Technology, vol. 39, no. 5, pp. 464-483, 2016.

[13] X. Li, J. Yu, J. Shaw, and Y. Wang, "Route-level transit operational-efficiency assessment with a bootstrap super-dataenvelopment analysis model," Journal of Urban Planning and Development, vol. 143, no. 3, p. 04017007, 2017.

[14] K. Zhang, Y. Xu, and D. Sun, "A mixed frontier model for urban bus performance evaluation," Proceedings of the Institution of Civil Engineers: Transport, vol. 171, no. 2, pp. 65-74, 2018.

[15] J.-S. Hahn, H.-R. Kim, and S.-Y. Kho, "Analysis of the efficiency of seoul arterial bus routes and its determinant factors," KSCE Journal of Civil Engineering, vol. 15, no. 6, pp. 1115-1123, 2011.

[16] Y. Lao and L. Liu, "Performance evaluation of bus lines with data envelopment analysis and geographic information systems," Computers, Environment and Urban Systems, vol. 33, no. 4, pp. 247-255, 2009.

[17] D. Sun, S. Chen, C. Zhang, and S. Shen, "A bus route evaluation model based on GIS and super-efficient data envelopment analysis," Transportation Planning and Technology, vol. 39, no. 4, pp. 407-423, 2016.

[18] R. Wei, X. Liu, Y. Mu, L. Wang, A. Golub, and S. Farber, "Evaluating public transit services for operational efficiency and access equity," Journal of Transport Geography, vol. 65, pp. 7079, 2017.
[19] K. Tone, "A slacks-based measure of efficiency in data envelopment analysis," European Journal of Operational Research, vol. 130, no. 3, pp. 498-509, 2001.

[20] K. Tone and M. Tsutsui, "An epsilon-based measure of efficiency in DEA - a third pole of technical efficiency," European Journal of Operational Research, vol. 207, no. 3, pp. 1554-1563, 2010.

[21] M. Tavana, H. Mirzagoltabar, S. M. Mirhedayatian, R. F. Saen, and M. Azadi, "A new network epsilon-based DEA model for supply chain performance evaluation," Computers \& Industrial Engineering, vol. 66, no. 2, pp. 501-513, 2013.

[22] J. Zhou, H. Pei, and H. Wu, "Early warning of human crowds based on query data from baidu maps: analysis based on shanghai stampede," in Big Data Support of Urban Planning and Management, pp. 19-41, Springer, 2018.

[23] China City Statistical Yearbook, China Statistics Press, 2016. 


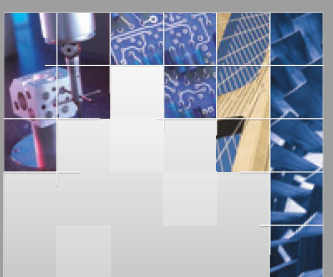

\section{Enfincering}
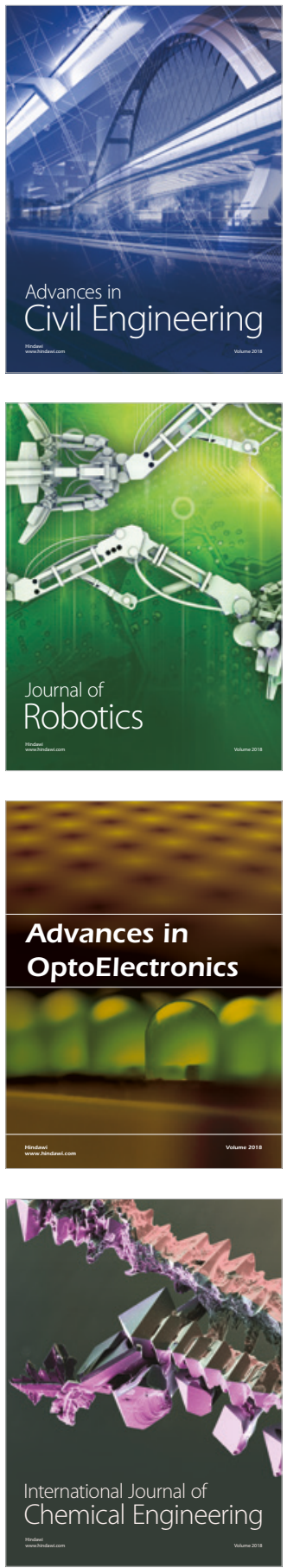

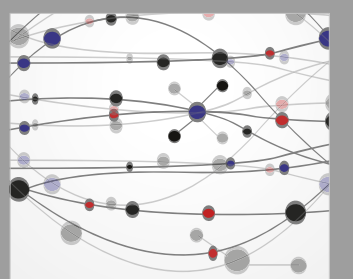

\section{Rotating \\ Machinery}

The Scientific World Journal

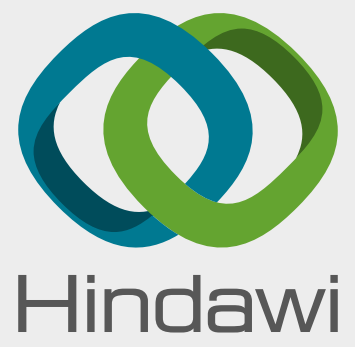

Submit your manuscripts at

www.hindawi.com
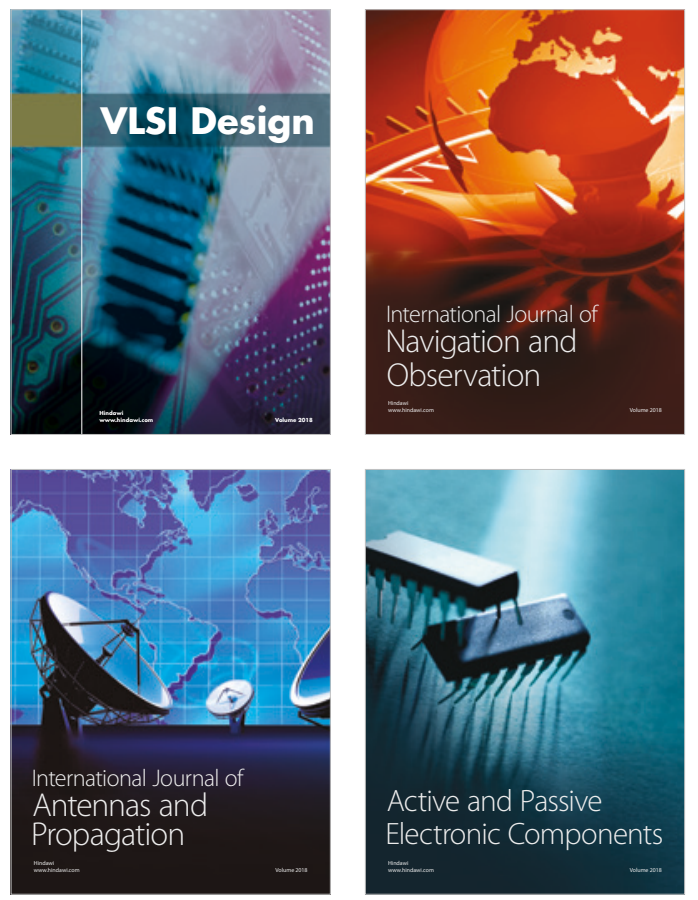
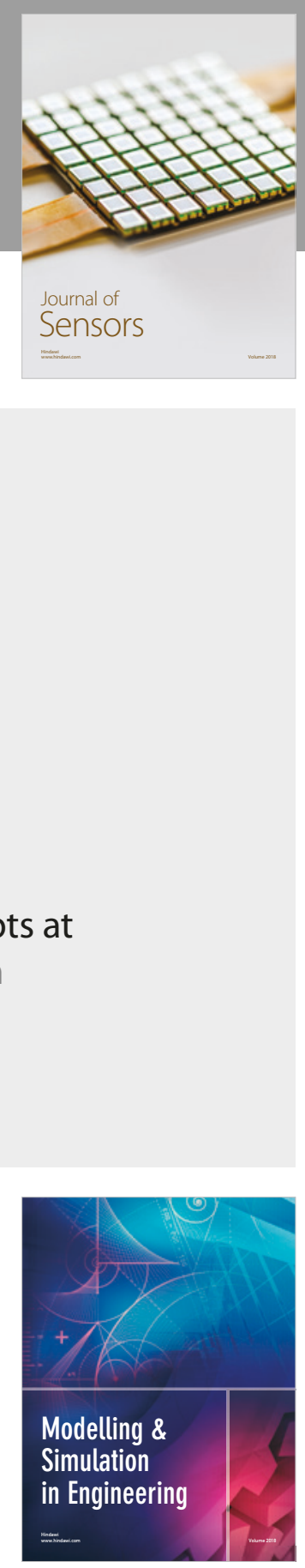

\section{Advances \\ Multimedia}
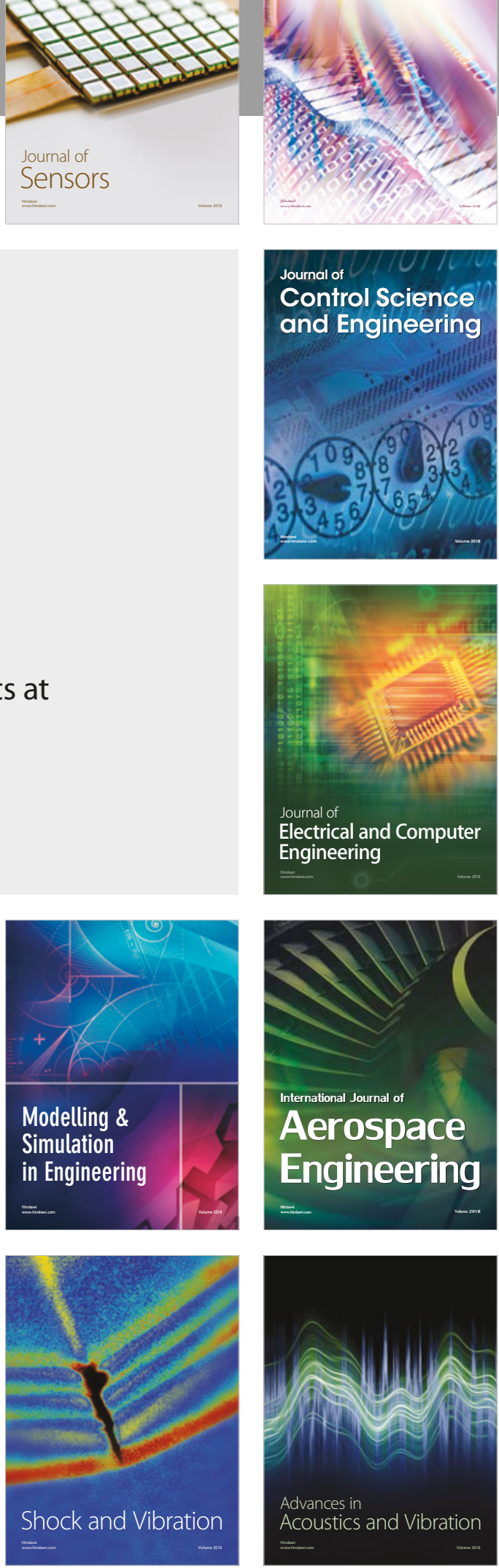